Proc. Estonian Acad. Sci. Eng., 2004, 10, 2, 123-136

\title{
Optical and electrical methods for pulse wave transit time measurement and its correlation with arterial blood pressure
}

\author{
Jaanus Lass ${ }^{\mathrm{a}}$, Kalju Meigas ${ }^{\mathrm{a}}$, Rain Kattai ${ }^{\mathrm{a}}$, Deniss Karai ${ }^{\mathrm{a}}$, Jüri Kaik ${ }^{\mathrm{b}}$, \\ and Mart Rossmann ${ }^{\mathrm{c}}$ \\ a Biomedical Engineering Centre, Tallinn University of Technology, Ehitajate tee 5, 19086 Tallinn, \\ Estonia; \{jaanus,Kalju,rain,deniss\}@cb.ttu.ee \\ b Estonian Institute of Cardiology, Ravi 27, 10138 Tallinn, Estonia; jyri.kaik@mail.ee \\ c Emros OÜ, P.O.Box 147, 11911, Tallinn, Estonia; rosmann@trenet.ee
}

Received 16 February 2004, in revised form 11 March 2004

\begin{abstract}
This paper gives an overview of a research, which is focused on the development of a convenient method for continuous non-invasive monitoring of the arterial blood pressure (BP). The method is based on the presumption that there is a single relationship between the pulse wave propagation time in arterial system and BP. The pulse wave transit time (PWTT) measurement involves the registration of two time markers, one of which is usually based on ECG registration and another on the detection of the pulse wave in peripheral arteries. This study makes a comparative evaluation of four different methods for pulse wave detection: 1) self-mixing in a diode laser, which can detect the skin surface vibrations near the artery, 2) photoplethysmography (PPG) that reflects volumetric changes in peripheral vasculature, 3) cardiosynchronized component of bioimpedance associated with blood displacement in the vascular system, and 4) direct pressure pulsations of finger arteries, detected noninvasively by the piezoelectric transducer. Linear correlation of PWTT, obtained with different methods, with arterial blood pressure is calculated. As a result of the current study it is shown that time intervals, which are calculated from PPG waveforms, are in good correlation with systolic BP during the exercise (linear correlation coefficient $r=-0.7$ ). At rest slightly better results are obtained by diode-laser pulse profile (LPP) sensor $(r=-0.9)$ as compared to PPG $(r=-0.87)$. The correlations of pulsatile bioimpedance (BI) sensor $(r=-0.57)$ and piezoelectric pulse wave $(\mathrm{PW})$ transducer $(r=-0.47)$ based PWTT calculations with arterial non-invative BP (NIBP) were not as good as for optical parameters (PPG, LPP). The diastolic BP did not correlate well with any of the parameters representing PWTT $(|r|<0.35)$. It is concluded that the PPG signal is the best for PWTT measurement. It is also most easily detectable and less sensitive to motion artefacts compared to other pulse signals.
\end{abstract}

Key words: blood pressure, optical self-mixing, bioimpedance, photoplethysmography, piezoelectric transducer, pulse wave transit time. 


\section{INTRODUCTION}

Arterial hypertension is a major problem in modern medicine and health-care since most people develop hypertension during their lifetime. Recent data from the Framingham Heart Study $\left[{ }^{1}\right]$ suggest that even for those individuals who are normotensive at age 55 , there is a $90 \%$ chance that they will eventually become hypertensive. It is a well-known demographic fact that as the population ages, the prevalence of hypertension will increase even further unless broad and effective preventive measures are implemented. As traditionally defined, hypertension (systolic BP greater than 140 and diastolic BP greater than $90 \mathrm{~mm} \mathrm{Hg}$ ) affects approximately 50 million individuals in the United States and about one billion persons worldwide. Hypertension remains a common and serious problem, contributing in a major way to the most common causes of morbidity and mortality in developed societies. The risks of elevated BP have been determined from largescale epidemiologic studies. It is estimated that the diastolic BP that is persistently higher by $5.0 \mathrm{~mm} \mathrm{Hg}$ increases at least for $34 \%$ the stroke risk and causes a $21 \%$ increase in coronary heart disease $\left[{ }^{2}\right]$. Improvements in the recognition and treatment of hypertension have played a major role in significant reduction of cardiovascular diseases over the past two decades. Nevertheless, a great gap between the three categories of people - those who are aware of their hypertension, those who are being treated, and those who are controlled - remains. Actually, more than $30 \%$ of the hypertensive populations are still unaware that they have hypertension, mainly because of the asymptomatic nature of the disease during the first 15-25 years, even when it progressively damages the cardiovascular system. Detailed information about the medical point of view on the problem can be found in the guideline of the Joint National Committee on Prevention, Detection, Evaluation, and Treatment of High Blood Pressure $\left.{ }^{3,4}\right]$.

The early detection of elevated BP is complicated by several factors, among them by the variability of the pressure by repeated measurements, both during a single visit and on repeated occasions, which is much greater than most physicians realize. The variability of BP can be detected in short-term, daytime and diurnal evaluation. The short-time variability at rest is affected by respiration and changes in the heart rate, which is controlled by autonomic nervous system. Daytime variability is determined by the degree of mental and physical activity mainly. Diurnal variability is substantial, with an average fall in BP for about $15 \%$ during sleep. That is why, whenever possible, office measurements should be supplemented by out-of-office measurements, particularly when an apparent gap between the level of BP and the degree of the target organ damage is present. Non-invasive and long term (up to $24 \mathrm{~h}$ ) ambulatory BP monitoring has become an important and useful tool for lowering cardiovascular risk and guiding therapy during the last 25 years. It provides multiple BP measurements during everyday activities and sleep; that gives the possibility to evaluate circadian variations of BP. It also exhibits closer correlation to surrogate end points (in case of left ventricular hypertrophy) than office blood pressure does, and is also more 
reproducible than clinic BP, since it can assess white-coat hypertension $\left[^{5}\right]$. In addition, ambulatory BP monitoring is essential for the detection of persistently elevated pressure during 2-3 h after awakening, when the largest proportion of sudden cardiac deaths, myocardial infarctions and strokes occur. Ambulatory BP recordings are of great use in the assessment of therapeutic intervention efficacy and treatment resistance.

Some technical problems of long term BP recording still exist. Commercially available monitors measure BP by means of auscultatory or oscillometric methods. The advantage of the first method is that movement does not interfere with the recording. However, these monitors are sensitive to background noise. The results of the second method are not affected by the background noise, but arm movement can cause errors. In addition, both measurement systems are based on the cuff, which is attached to the patient's arm, and central unit containing the pump and memory chip. That causes certain personal discomfort. The monitors are usually pre-programmed to make records at every 15-20 min, which can cause inconveniences by everyday activities and a loss of important information between the measurements.

A potentially useful and convenient parameter for continuous monitoring of the blood pressure could be pulse wave velocity or PWTT between different regions of the human body $\left[{ }^{6,7}\right]$. It is suggested that although it may be difficult to estimate systolic BP from PWTT with acceptable accuracy, possibilities remain to utilize changes in pulse arrival time as an indicator of changes in systolic BP. During the exercise, arterial BP increases, which is mainly achieved by increasing the contractility of the heart and vasculature resistance. Both of these values result in the increase of the pressure wave speed in the vascular system, which means that the time delay between the start of electromechanical contraction and PWTT at any particular point in the body decreases. Several of our previous studies have shown that it is possible to calculate the mean arterial pressure from PWTT $\left.{ }^{8-10}\right]$. Current work is an extension of these studies and is mainly focused on the comparison of different pulse wave detection methods like self-mixing in a diode laser, which can detect skin surface vibrations near the artery, photoplethysmography that reflects volumetric changes in vasculature, pulsatile bioimpedance associated also with blood displacement in vascular system, and direct pressure pulsations of finger arteries detected by the piezoelectric transducer.

\section{MATERIALS AND METHODS}

\subsection{Optical methods for pulse wave detection}

\subsubsection{Diode-laser motion sensor based on self-mixing}

The pulse as a pressure wave causes changes in the radius of blood vessels and in the movement of their wall. Typically, vessel wall expansion and shrinkage results in the movement of the skin surface, which can reveal the pulsatile propagation of pulse waves along the vasculature and can contain such 
useful parameters as period of pulsation, the moment of the pulse wave arrival and pulsation profile. An optical coherent method, using photodetection in a diode laser, may be used for blood vessels profile registration. An experimental device with pigtail laser diode has been developed. This device is able to detect pulsation profiles of major arteries with potentially useful information, including pulse wave velocity and profile of the pulse pressure. The basis of the registration is self-mixing that occurs in the diode laser cavity when the radiation, scattered back by the skin into the laser, interferes with the field inside it and causes the changes of the laser pump current. These changes can be registered in two different ways simultaneously: by using a photodiode, accommodated in the rear facet of the diode laser package, and with a small resistance resistor in the chain of the laser pump current. For the detection of LPP, the probing ray was led via the optical fibre to the skin surface where the arteries are close to the skin, for example, radial artery in the wrist or carotid artery in the neck. At the end of the fibre a special clamp was attached to minimize the interfering signal due to involuntary tremor of the body (position of the fibre tip relative to the skin surface was fixed). The signals were recorded with a sampling rate of $10 \mathrm{kHz}$, which gives a bandwidth of $0-5000 \mathrm{~Hz}$. The recorded signal needs pre-processing in order to extract pulse wave parameters. For that purpose FFT inside the sliding window was computed; the length of the Hanning windowed signal was 128 points and power spectrum was calculated after every 8 points (resolution $0.8 \mathrm{~ms}$ ) using the FFT algorithm. From every calculated power spectrum segment the frequency with maximum amplitude was detected, which gives the timedependent Doppler frequency (pulse profile). We used the National Instruments data acquisition board NI DAQ AT-M10-16E-10 to digitize the signals locally and transmit the digital data to the PC with a resolution of 12 bit. More detailed description of the device and choice of the pre-processing parameters can be found in $\left[{ }^{9,11}\right]$. The advantage of the method is that theoretically the measurement can be done without any mechanical influence on the artery.

\subsubsection{Photoplethysmographic sensor}

Plethysmography is a term for non-invasive volume change measurement inside the body. Photoplethysmography is based on the determination of the optical properties of a selected tissue volume. For this purpose the light is emitted into the tissue where a part of it is absorbed and a part is scattered back. The wavelength of the light is chosen so that it is absorbed well in blood and in such a way the relative blood volume changes can be determined by detecting the absorbed or scattered light. The detected heart rate frequency component of the light in a localized volume of the tissue that is caused by blood being forced into vessels characterizes the volumetric pulse wave.

Photoplethysmography is widely used for pulse wave registration; the same method is implemented in several commercial products like pulse oximetry devices. Photoplethysmorgraphic signal can be detected theoretically from every part of the human body and it is quite widely used for pulse wave velocity and 
PWTT measurements $\left[{ }^{12-15}\right]$. Different sensors are made commercially available for fingers, earlobe, nose, forehead, etc. In our study we used a laboratory device that was equipped with two different commercial sensors - a fingersensor Duraclip $^{\mathrm{TM}}$ (Minnesota Med-Equip, USA) and an earsensor E-412 (Epic Medical Equip., USA). Both of them work in transmission mode. Only the infrared channel of the sensors was used in our experiments.

\subsection{Electrical methods for pulse wave detection}

\subsubsection{Bioimpedance sensor}

Bioimpedance measurement, sometimes also called impedance plethysmography, can detect cardiosynchronized (pulsatile) changes of resistance inside a certain body segment. That particular component of bioimpedance is produced by blood displacement inside the tissue and is directly proportional to the volumetric wave. The electrical bioimpedance is measured by passing a small amount of alternating current through the body segment. A special laboratory instrument was designed for thoracic impedance measurements. The device was based on a lock-in measurement method and used current $10 \mu \mathrm{A}$ at a frequency of $100 \mathrm{kHz}\left[{ }^{16}\right]$.

\subsubsection{Piezoelectric transducer}

A relatively simple electrical method for the detection of the pressure wave is based on a piezoelectric transducer, which generates a measurable voltage when a deforming mechanical force is applied. The deformation produces voltage that is amplified and thereafter a data acquisition card records it. The method has been successfully used in pulse wave velocity measurements $\left[{ }^{12}\right]$. In our study we detected the piezoelectric pressure wave from the middle finger. A commercially available pulse transducer MP100 (ADInstrument, Australia) was used for that purpose.

\section{REGISTRATION SYSTEM}

Our laboratory registration system is modular and based on NI DAQ AT-M10$16 \mathrm{E}-10$ with multiple A/D conversion channels and a PC with graphical software LabVIEW. Different analogue signal conditioning modules can be switched to the system either for sequential or simultaneous registration purposes. Four of our signal conditioning modules, capable to detect pulse signals of LPP, PW, PPG and $\mathrm{BI}$ are already discussed above. Additionally, a laboratory ECG module for single channel ECG registration belongs to the system. With the data acquisition user interface, during an experiment manual insertion of non-invasive blood pressure values is possible. The inserted values are automatically synchronized with other continuously recorded signals. The sampling frequency for laser self-mixing signal is $10 \mathrm{kHz}$ and for other signals $1 \mathrm{kHz}$. 


\section{SUBJECTS AND EXPERIMENTAL PROTOCOLS}

Two different experiments were conducted in this study. During the first experiment, optical pressure wave and a volumetric wave were compared. For that purpose the ECG, PPG and LPP signals were recorded simultaneously in a group of healthy subjects, 11 persons with the mean age of $22 \pm 4$ years ( 4 female and 7 male). To increase the arterial blood pressure a bicycle test was used. The test consisted of cycling sessions of increasing workloads during which the heart rate (HR) changed from 60 to 180 beats per minute. The probing ray was guided via an optical fibre of $1 \mathrm{~m}$ length, which is included in a package of pigtail laser diode, to the skin surface on the neck (carotid artery measurements were performed in this case). A special clamp was attached to the end of the fibre to minimize the interfering signal due to involuntary body tremor (the position of fibre tip relative to the skin was fixed). The ECG signal was recorded between the upper limbs. For PPG signal registration the ear sensor was used. Blood pressure was measured with standard device Omron IC using an oscillometric method. The signals were recorded at the end of every cycling session within $10 \mathrm{~s}$. In order to reduce artefacts, caused by body movements during the exercise, the cycling was stopped for the recording period. In average 8-15 recording cycles were made during one test. An episode of the recorded signals is presented in Fig. 1. From the ECG the R-peaks were detected by adaptive level peak detector and thereafter the maximums of pulse signals were found. Starting points of the pulse signals were pre-allocated with the help of the first derivative of the signals. All detection points were thereafter verified and, if necessary, adjusted manually. Special software was designed for manual verification of the detection points. From the detected markers the PWTT was calculated as the time interval between the R-peak of ECG and pulse signal starting point. The measured PWTT intervals were averaged over each 10-s recording episode. The calculations of PWTT were made separately for LPP and PPG signals.

During the second session, the ECG, PPG, PW and BI signals were recorded simultaneously for a group of volunteers (34 persons). The volunteers represented different patients with different diseases with the mean age of $46 \pm 14$ years (14 female and 20 male). Similarly to the first session, the test consisted of cycling sessions of increasing workloads during which the HR changed from the resting rate to submaximal. At the end of every test a recovery period started until the person's HR normalized. All signals, except NIBP, were recorded continuously. An example of the recording episode can be seen in Fig. 2. The NIBP was registered with standard sphygmomanometer once per minute. The NIBP measurement values were synchronized with other signals at time moments when the systolic BP was detected (Korotkoff sound's starting point). The computer later interpolated the blood pressure signal in order to get individual value for every heart cycle.

Laboratory signal processing software was used to detect the pulse parameters and to calculate PWTT between ECG and other signals, which reflect the pulse 

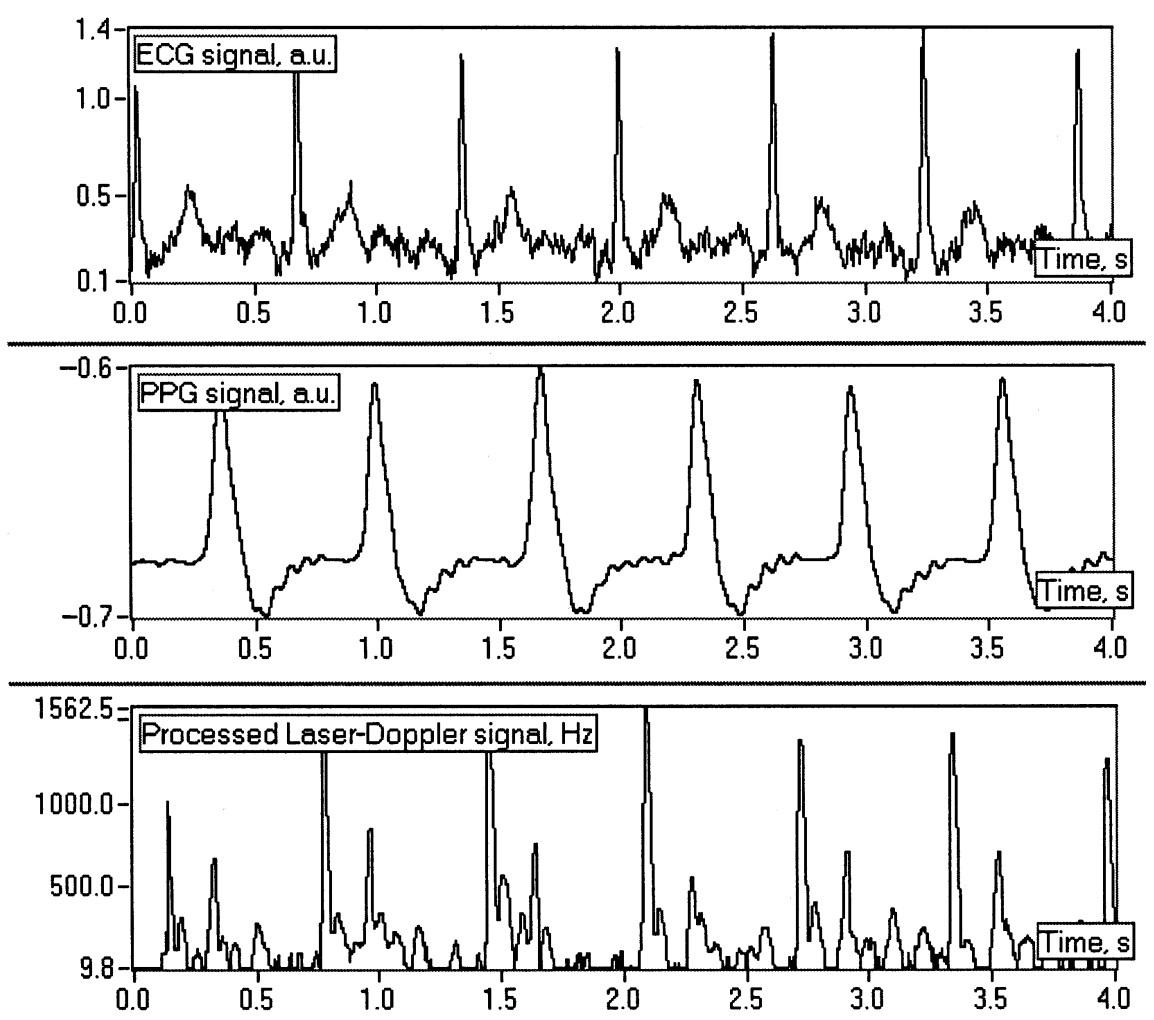

Fig. 1. An illustration of recorded signals; the PPG signal is recorded with the ear sensor and the LPP signal from the carotid artery.

wave propagation in the vascular system. First task for the processing algorithm was to determine the locations of R-peaks in ECG. For that purpose, slightly modified Tompkins algorithm was used $\left[{ }^{17}\right]$. In the beginning, the signal was filtered by low- and high-pass filters in order to maximize QRS-complexes and to suppress all other waves in ECG. Then the first derivative of the signal was calculated and squared; these operations increased the magnitudes of QRS complexes compared to the rest of the signal. After that the moving average of the signal was calculated (the window length was $80 \mathrm{~ms}$ ). This operation smoothed the QRS complexes, enabling more stable detection. The next operation was to use adaptive level pulse detector that detects the rising edges of the pulses in the signal as locations of the R-peaks. Adaptive level was formed as $50 \%$ of average amplitude of the signal of last 10-s window with the step of $2 \mathrm{~s}$. A couple of $\mathrm{R}$-peak post-classification rules were also used in order to enhance correct R-peak detection. These rules were as follows:

1) ignore all peaks that occur after the detection during the first $200 \mathrm{~ms}$;

2) when there is a peak less than $360 \mathrm{~ms}$ from the previous detection, check if the derivative of the signal is more than $50 \%$ of the derivative of the last detection point; 


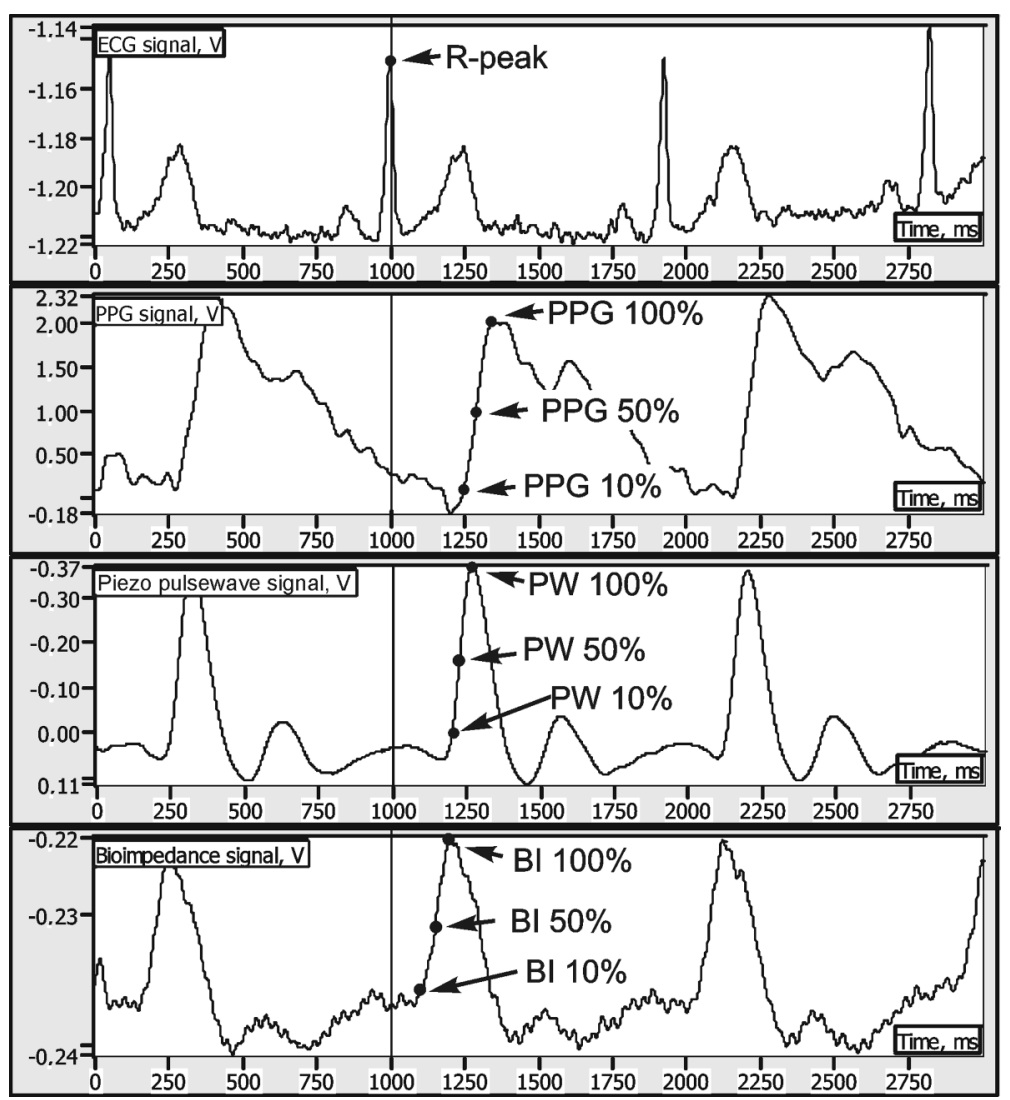

Fig. 2. An illustration of recorded signals and detected time markers; the PPG signal is recorded from the index finger, the piezoelectric PW signal is recorded from the middle finger and the BI signal is recorded from upper limbs.

3) when there is no R-peak detected during the $1.5 \mathrm{RR}$ interval and inside that window there is a peak with an amplitude of more than $50 \%$ of the adaptive detection level and the peak is at least $360 \mathrm{~ms}$ away from the last detection, the peak should be detected as a valid R-peak.

The next step in signal pre-processing was the calculation of pulse wave parameters for different pulse signals. Since all the pulse signals were similar, the same algorithm was applicable. The method for pulse wave detection was quite robust and based on the correct R-peak detection. Initially, the pulse signals were high-pass filtered in order to reduce baseline fluctuations; the cut-off frequency of the filter was $0.5 \mathrm{~Hz}$. At $150 \mathrm{~ms}$ after each valid R-peak location, the corresponding pulse wave search window was formed (the window length was $350 \mathrm{~ms}$ ). Inside that window, the maximum value of the signal is found and named as the peak of the pulse wave (PPG $100 \%$ for example). Thereafter the initial search window is cut to the index of pulse wave maximum and the minimum value of the signal inside that window was detected. The starting point 
for the pulse wave was determined as a $10 \%$ increase of the signal amplitude from the minimum point towards maximum. The $50 \%$ values of the pulse signals were calculated following this rule (Fig. 2).

\section{RESULTS AND DISCUSSION}

An example of recorded signals of the first experimental series is shown in Fig. 1. The Pearson's correlation coefficient is used for estimating the relationships between the calculated parameters. Average correlation coefficients for a group of parameters are shown in Table 1. From the table we can see that the best correlation with systolic blood pressure has LPP $(r=-0.9)$, the correlation of PPG is slightly lower $(r=-0.868)$. The volumetric and pressure signals correlate very well. The correlation with diastolic pressure and pulse signals is much lower. One reason for slightly better correlation of LPP with systolic pressure as compared to PPG could be the much sharper rising front of LPP (Fig. 1) that makes the measurement more precise. Another reason for that could be the native difference of volumetric and pressure waves. At the same time it can be seen that the correlation between PPG and LPP is also very high $(r=0.91)$, which could mean that there is no remarkable qualitative differences in PWTT measurements on the basis of the volumetric or pressure signals. Despite the fact that the results of these experiments revealed small advantage of LPP by PWTT measurement, the method has also many disadvantages. The signal itself is very sensitive to motion and even in a signal without artefacts there are usually many clear and concurrent peaks and this makes the automatic detection of the signal starting point very difficult. Moreover, detection of the LPP signal itself requires much more computing power and memory compared to PPG because of much higher frequencies and an extra frequency to voltage converter.

Mainly because of these difficulties in LPP signal detection during the exercise, it was decided not to use the method in our next experimental design. The LPP was replaced with the piezoelectric pressure wave sensor, and a bioimpedance sensor as a concurrent volumetric sensor for photoplethysmography was added in that experimental series. An example of the recording results is presented in Fig. 2. There are also different pulse wave detection markers 10\%, 50\% and 100\% shown in that figure. As it can be seen from the figure, the earliest detection point can be located in BI signal (BI 10\%) compared to PW and PPG. Time between the signal

Table 1. Average correlation coefficients of calculated parameters for the first experimental series $(p<0.05)$

\begin{tabular}{|l|c|c|c|}
\hline & LPP & PPG & Systolic \\
\hline LPP & & & \\
\hline PPG & 0.914 & & \\
\hline Systolic & -0.901 & -0.868 & \\
\hline Diastolic & -0.354 & -0.339 & 0.544 \\
\hline
\end{tabular}


of the electrical activity QRS complex of the heart and pulse wave arrival is related mainly to the PWTT, but there is also another important parameter called isovolumic contraction time or pre-ejection period (PEP). It is the interval required for the heart to convert the electrical stimulus into a productive mechanical contraction capable of ejecting blood from the ventricles. This time interval contributes to the delay between ECG Q-peak and aortic valve opening. This period has been shown to be uncorrelated with arterial pressure and may make up a substantial part of the ECG-peripheral pulse delay $\left[{ }^{18}\right]$. This means that the detected bioimpedance pulse is formed mostly by the changes in blood volume near to the heart. Thus it can be inferred that isovolumic contraction period is the main component in PWTT that is calculated on the basis of the time marker BI10. It is also in good agreement with PEP calculation algorithms in impedance cardiography $\left[{ }^{19}\right]$. The next signal that can be triggered is mechanical pulse pressure wave (PW10), which represents the moment when the arterial pulse pressure starts to increase in the major arteries of the middle finger. The last wave front that can be detected is PPG (PPG10), which is the starting point of blood volume changes in the index finger. This kind of measurement set-up allows us to estimate the isovolumic contraction time (BI10) and the pulse pressure propagation time (PW10-BI10) and to compare the changes in these parameters with other intervals and with NIBP. It should be mentioned that the average BI10 values were higher than expected, which could mean that BI10 does not represent the true isovolumetric phase but also extends to the beginning of the ejection phase. Nevertheless, BI10 is the only parameter in this set where the isovolumic phase has an essential part.

In Fig. 3, we can see the changes of some of the calculated parameters during the exercise for one person from the group. It can be noticed that whereas BW10 and BI10 are inversely proportional to the systolic arterial blood pressure, the PW10-BI10 curve does not correlate well with other curves. The same result is valid for the whole group (Table 2). Table 2 is the average correlation matrix for the study group for all calculated parameters giving the Pearson's correlation coefficients. From the table we can see that the best correlation with systolic blood pressure has PPG10. It is the only parameter the correlation of which is more than -0.7. Dynamic range of PPG10 and systolic pressure is approximately the same $(1 \mathrm{~mm} \mathrm{Hg} \sim 1 \mathrm{~ms})$. The parameters PPG50 and PPG100 have slightly lower correlation coefficients. Parameters BI and PW have much lower correlation with systolic blood pressure compared to PPG. From the table it can be seen that diastolic pressure does not correlate with any of the parameters. The reason is that in several cases diastolic pressure, registered by the oscillometric or auscultatory method, did not change remarkably during the exercise and in some cases even showed a decreasing trend when the workload was increased. This leads us to the conclusion that diastolic pressure cannot be estimated reliably only by PWTT measurement. In Table 2 there is also a parameter PPG100PPG10, which represents the rising time of the PPG pulse wave; it can be seen that it does correlate with blood pressure changes $(r=-0.25)$. This means that the 
change in the rising time of the pulse signal cannot be a reliable parameter for arterial pressure estimation.
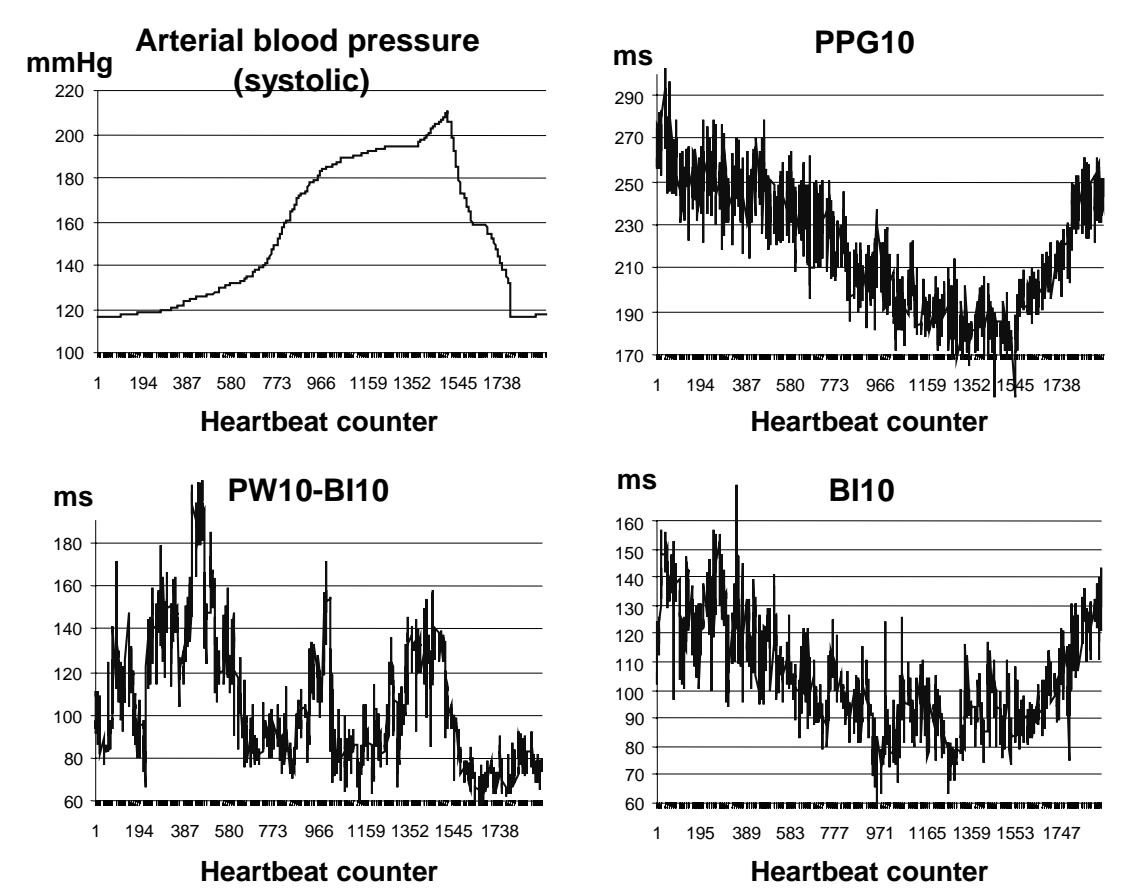

Fig. 3. An example of calculated parameters during the exercise.

Table 2. Average correlation coefficients of calculated parameters for the whole group of the second experimental series $(p<0.05)$

\begin{tabular}{|l|c|c|c|c|c|c|c|c|c|c|c|c|}
\hline & PPG100 & PPG10 & PPG50 & PW100 & PW10 & PW50 & BI100 & BI10 & BI50 & $\begin{array}{c}\text { PW10- } \\
\text { BI10 }\end{array}$ & $\begin{array}{c}\text { PPG100- } \\
\text { PPG10 }\end{array}$ & Systolic \\
\hline PPG100 & & & & & & & & & & & & \\
\hline PPG10 & 0.681 & & & & & & & & & & & \\
\hline PPG50 & 0.755 & 0.849 & & & & & & & & & & \\
\hline PW100 & 0.480 & 0.520 & 0.532 & & & & & & & & & \\
\hline PW10 & 0.420 & 0.481 & 0.448 & 0.655 & & & & & & & & \\
\hline PW50 & 0.490 & 0.514 & 0.515 & 0.784 & 0.761 & & & & & & & \\
\hline BI100 & 0.320 & 0.461 & 0.427 & 0.446 & 0.445 & 0.446 & & & & & & \\
\hline BI10 & 0.375 & 0.448 & 0.416 & 0.351 & 0.309 & 0.339 & 0.328 & & & & & \\
\hline BI50 & 0.481 & 0.587 & 0.585 & 0.452 & 0.356 & 0.458 & 0.516 & 0.491 & & & & \\
\hline $\begin{array}{l}\text { PW10- } \\
\text { BI10 }\end{array}$ & -0.077 & -0.198 & -0.168 & -0.037 & 0.144 & 0.049 & 0.009 & -0.030 & -0.224 & & & \\
\hline $\begin{array}{l}\text { PPG100 } \\
\text {-PPG10 }\end{array}$ & 0.484 & 0.251 & 0.324 & 0.198 & 0.179 & 0.213 & 0.122 & 0.199 & 0.223 & 0.105 & & \\
\hline Systolic & -0.620 & $-\mathbf{0 . 7 0 0}$ & -0.674 & -0.500 & -0.381 & -0.474 & -0.374 & -0.392 & -0.578 & 0.358 & -0.246 & \\
\hline Diastolic & 0.212 & 0.163 & 0.198 & 0.120 & 0.102 & 0.141 & 0.140 & 0.175 & 0.116 & 0.203 & 0.168 & -0.046 \\
\hline
\end{tabular}




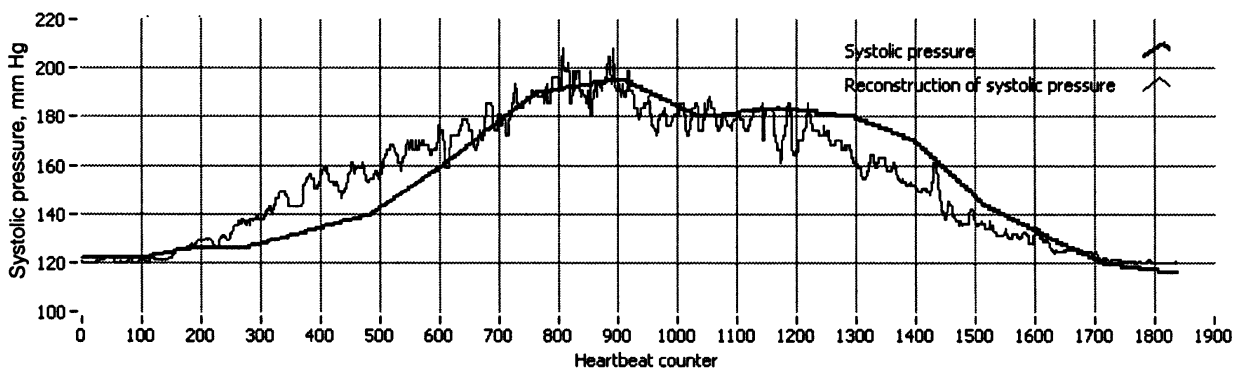

Fig. 4. An example of systolic pressure reconstruction during the bicycle exercise; bold curve represents measured systolic pressure interpolation line and regular curve represents the results of calculation based on PPG50 and interpolated systolic pressure data.

An example of the arterial blood pressure reconstruction is shown in Fig. 4. Both the exercise and recovery phase are shown in the figure - the exercise was stopped at around 900 heartbeats. The reconstruction is performed with the help of PPG50 and is based on the best polynomial fit (4th order) between the spyghmomanometrically measured NIBP (interpolated values) and PPG50. The parameter PPG50 was median filtered (order 5) before the fitting procedure in order to eliminate possible misdetections of PWTT during intensive exercise. Figure 4 shows that PPG50 tends to overestimate the systolic pressure in the beginning of the exercise and to underestimate it in certain phases of the recovery. This leads us to the assumption that even a better reconstruction could be achieved with taking into account an extra parameter that monitors the phase or intensity of the exercise. That could be additional accelerometric sensor or just a trend-monitoring algorithm for HR.

\section{CONCLUSIONS}

1. The correlation of systolic NIBP with PWTT, calculated on the basis of LPP, is only slightly better than on the basis of PPG. The LPP signal registration is more complicated and due to higher bandwidth it requires much more computational power compared to PPG.

2. The correlation of NIBP with PWTT, calculated on the basis of PPG, is better as compared to PW- or BI- based PWTT calculation. One reason for that could also be registration problems during an intensive exercise.

3. There is no major qualitative differences in correlation with systolic NIBP weather the PWTT is calculated on volumetric or pressure based signals. Comparing optical and electrical methods, it can be concluded that optical methods are more reliable for pulse wave detection.

4. The best overall correlation with systolic NIBP during the exercise had the parameter PPG10, that is the time interval from R-peak (ECG) to the plethysmographic pulse starting point. Since PPG10 and PPG50 possess similar properties, 
PPG50 should be preferred in conditions of heavy exercise because PPG50 is less sensitive to motion artefacts.

5. The diastolic pressure has weak correlation with any of the studied parameters, representing PWTT.

6. Isovolumic contraction time, measured by $\mathrm{BI}$, correlates with arterial $\mathrm{BP}$ much better than the pulse pressure propagation time (PW-BI). This finding is not in a good agreement with earlier studies and needs to be investigated further.

\section{ACKNOWLEDGEMENT}

This study has been supported by the Estonian Science Foundation (grant No. 5888) and Estonian Technology Agency.

\section{REFERENCES}

1. Vasan, R. S., Larson, M. G., and Leip, E. P. Assessment of frequency of progression to hypertension in non-hypertensive participants in the Framingham Heart Study: a cohort study. Lancet, 2001, 358, 1682-1686.

2. Kaplan, N. M. Clinical Hypertension. Williams \& Wilkins, Baltimore, 1998.

3. Chobanian, A. V., Bakris, G. L., Black, H. R., Cushman, W. C., Green, L. A., Izzo, J. L., Jones, D. W., Materson, B. J., Oparil, S., Wright, J. T., et al. The seventh report of the Joint National Committee on Prevention, Detection, Evaluation, and Treatment of High Blood Pressure. JAMA, 2003, 289, 2560-2572.

4. The sixth report of the Joint National Committee on Prevention, Detection, Evaluation, and Treatment of High Blood Pressure. Arch. Intern. Med., 1997, 157, 2413-2446.

5. Ernst, M. E. and Bergus, G. R. Ambulatory blood pressure monitoring, South Med. J., 2003, 96, $563-568$.

6. Lutter, N., Engl, H. G., Fischer, F., and Bauer, R. D. Non-invasive continuous blood pressure control by pulse wave velocity. Z. Kardiol., 1996, 85, Suppl. 3, 124-126.

7. Sugo, Y., Tanaka, R., Soma, T., Kasuya, H., Sasaki, T., Sekiguchi, T., Hosaka, H., and Ochiai, R. Comparison of the relationship between blood pressure and pulse wave transit times at different sites. In Proc. First Joint BMES/EMBS Conference Serving Humanity, Advancing Technology. Atlanta, 1999, CD-ROM.

8. Meigas, K., Kattai, R., and Lass, J. Pulse wave time delay for blood pressure monitoring. In Proc. International Federation for Medical and Biological Engineering, 2002, Vol. 2, 54-55.

9. Meigas, K., Hinrikus, H., Kattai, R., and Lass, J. Self-mixing in a diode laser as a method for cardiovascular diagnostics. J. Biomed. Opt., 2003, 8, 152-160.

10. Tepner, I., Lass, J., Karai, D., Hinrikus, H., and Meigas, K. Monitoring blood pressure from pulse wave transit time. In Proc. 4th BSI International Workshop. Como, 2002, 239-242.

11. Meigas, K., Kattai, R., and Lass, J. Optimising of signal processing parameters in cardiovascular diagnostics. In IFMBE Proc. IX Mediterranean Conference on Medical and Biological Engineering and Computing. Pula, 2001, Part 1, 328-331.

12. McLaughlin, J., McNeill, M., Braun, B., and McCormack, P. D. Piezoelectric sensor determination of arterial pulse wave velocity. Physiol. Meas., 2003, 24, 693-702.

13. Loukogeorgakis, S., Dawson, R., Phillips, N., Martyn, C. N., and Greenwald, S. E. Validation of a device to measure arterial pulse wave velocity by a photoplethysmographic method. Physiol. Meas., 2002, 23, 581-596.

14. Ochiai, R., Takeda, J., Hosaka, H., Sugo, Y., Tanaka, R., and Soma, T. The relationship between modified pulse wave transit time and cardiovascular changes in isoflurane anesthetized dogs. J. Clin. Monit. Comput., 1999, 15, 493-501. 
15. Nitzan, M., Khanokh, B., and Slovik, Y. The difference in pulse transit time to the toe and finger measured by photoplethysmography. Physiol. Meas., 2002, 23, 85-93.

16. Min, M. and Parve, T. Current mode signal processing in lock-in instruments for bioimpedance measurement. Med. Biol. Eng. Comput., 1996, 34, suppl. 1, 167-168.

17. Tompkins, W. J. Biomedical Digital Signal Processing: C-Language Examples and Laboratory Experiments for the IBM PC. Prentice Hall, Englewood Cliffs, 1993, 236-263.

18. Koch-Wesser, J. and Blinks, J. R. The influence of the interval between beats on myocardial contractivity. Pharmacol. Rev., 1963, 15, 602-652.

19. Sramek, B. B. Thoracic electrical bioimpedance: Basic principles and physiologic relationship. Noninvas. Cardiol., 1994, 3, 83-88.

\title{
Pulsilaine leviaja määramine optiliste ja elektriliste meetoditega ning selle korrelatsioon arteriaalse vererõhuga
}

\author{
Jaanus Lass, Kalju Meigas, Rain Kattai, Deniss Karai, Jüri Kaik \\ ja Mart Rossmann
}

Artikkel annab ülevaate uurimistööst, mille eesmärgiks oli arteriaalse vererõhu löögilt lööki mitteinvasiivne määramine. Meetod põhineb eeldusel, et eksisteerib ühene sõltuvus arteriaalse pulsilaine levikiiruse ja vererõhu vahel. Pulsilaine leviaja (PWTT) registreerimine kujutab endast kahe ajamarkeri detekteerimist (esimene ehk algusmarker pärineb EKG-signaalist ning teine ehk lõpumarker pulsilainelt veresoonkonna perifeersetes arterites). Töö käigus teostati nelja erineva pulsilaine registreerimismeetodi võrdlev analüüs: 1) nahalähedaste arterite võngete detekteerimine isesegustusefektil baseeruva dioodlaseriga, 2) fotopletüsmograafia, mis peegeldab verehulga muutusi veresoonkonnas, 3) südamesageduslike bioimpedantsimuutuste mõõtmine, mis samuti peegeldab verehulga ümberpaiknemist soonkonnas, ning 4) südamesageduslike rõhumuutuste mitteinvasiivne detekteerimine sõrmearterites piesoelektrilise anduriga. Erinevate meetoditega arvutatud PWTT ja vererõhumuutuste vahelise seose hindamisel on aluseks lineaarne korrelatsioonikordaja $r$. Töö tulemusena leiti, et pulsilaine leviajad, mis on arvutatud fotopletüsmograafilise signaali (PPG) baasil, on heas korrelatsioonis süstoolse vererõhu muutustega füüsilise koormuse korral $(r=-0,7)$. Rahulikus olekus registreeritud pulsilainesignaalidest arvutatud ülekandeaegadest korreleerub süstoolse vererõhuga laserdioodanduri baasil arvutatud leviaeg $(r=-0,9)$ paremini kui PPG baasil arvutatu $(r=-0,87)$. Kardiosünkroniseeritud bioimpedantsi $(\mathrm{BI})(r=-0,57)$ ja piesoelektrilise pulsilaine $(r=$ $-0,47)$ baasil arvutatud PWTT korrelatsioonid arteriaalse vererõhuga olid optilisi meetodeid kasutavate leviaja arvutustega võrreldes madalamad. Diastoolne vererõhk on PWTT muutustega väga nõrgas korrelatsioonis $(|r|<0,35)$ kõikide vaadeldud parameetrite ja andurite korral. Töö tulemusena järeldatakse, et PPG-signaali baasil arvutatud PWTT on arteriaalse vererõhu muutuste hindamiseks parim, kuna see on lihtsalt registreeritav, korreleerub hästi süstoolse vererõhuga ning on uuritud signaalidest kõige väiksema tundlikkusega liigutustest põhjustatud häirete suhtes. 